\title{
The Conflict Management Grid: A Selection and Development Tool to Resolve the Conflict between the Marketing and Sales Organizations
}

\author{
Nermine Magdy Atteya ${ }^{1}$ \\ ${ }^{1}$ Department of Marketing and Management, School of Business, State University of New York at Oswego, \\ New York 13126, USA; and The Modern Academy for Computer Science and Management Technology, Cairo \\ 11435, Egypt \\ Correspondence: Nermine Atteya, Department of Marketing and Management, School of Business, State \\ University of New York at Oswego, Oswego, New York 13126, USA. Tel: 1-315-312-3287. E-mail: \\ natteya@oswego.edu
}

Received: April 1, 2012

doi:10.5539/ijbm.v7n13p28

\author{
Accepted: April 28, 2012 \\ Published: July 1, 2012 \\ URL: http://dx.doi.org/10.5539/ijbm.v7n13p28
}

\begin{abstract}
The rapid globalization of modern business and the challenges to reach sales objectives within tough selling conditions pose major issues for human resource management. One important area that has yet to be fully explored is the management of conflict between sales and marketing functional areas in tough selling conditions. We hypothesize that: 1) marketing and sales task conflict is more likely to involve distributive (win-lose) issues and 2) when win-win (integrative) potential exists, the disputants are more likely to approach conflict from a fixed-pie perspective. Our analysis of data collected from food manufacturing industry supports this hypothesis. The application of different conflict management strategies varies depending on whether they are applied to sales or marketing task conflict. The importance of aligning conflict management strategies with the integrative potential of sales and marketing tasks is presented to managers.
\end{abstract}

Keywords: conflict management, conflict management strategies, sales function, marketing function, conflict management grid, tough selling

\section{Introduction}

\subsection{The Problem and Its Importance}

In the aftermath of the January 25th Revolution, Egyptian businesses find themselves facing tighter credit markets, restricted cash flows and labor unrest that have affected revenues and production. What happens in the food manufacturing industry is a microcosm of what happens to all the industry sector ; but it is more sensitive to production, market distribution and shipping delays, and problems show up faster" says Mostafa El Halgawy, director of corporate projects at Americana Group, one of the region's leaders in food manufacturing (Meuse and Walby, 2011), in addition of employing a high percentage of the active working population.

Tough selling conditions in addition to internal conflicts between the Marketing and Sales functions have remarkable effects on performance and consequently on sales and revenues. Conflict is a phenomenon that has existed and continues to hamper most organizations (Le Nguyen and Larimo, 2011; Bobot, 2010; Boros et al., 2010; Jehn, 1995; Kim et al., 2007). Individuals involved in organizations are consciously or unconsciously subject to conflict, and the positive and negative impact of conflict is unpreventable (Jehn, 1997). Sometimes conflict within organizations hasled to disturbed routines, and decreased productivity and satisfaction (Jehn, 1995). However, through conflict, an organization has the potential to enhance its quality of decision making, creativity, and performance (Jehn, 1997; Leung and Tjosvold, 1998; Tjosvold, 1998). Since conflict has important implications for organizations and performance, it is necessary to examine the causes and effects of this important organizational variable.

Management scholars described Conflict Management Strategies (CMSs) as "specific behavioral patterns that individuals prefer to employ when dealing with conflict" (Moberg, 2001, p. 47). A previous study divided CMSs into five strategies: integrating, obliging, dominating, avoiding, and compromising (Rahim, 1983). Research 
suggests that there is a preference for individuals to use the integrating strategy and the compromising strategy when facing conflicts (Trubisky et al., 1991; Lee, 2003). Gross and Guerrero (2000) proposed that an integrating strategy was a more effective form of conflict management strategy when compared with other CMSs. Even though integrating and compromising strategies are more likely to be used, few studies have investigated the antecedents of these CMSs (Antonioni, 1998). Among the limited research, Antonioni (1998) investigated the role of personality as an antecedent of CMSs. It was found that the role of extraversion, conscientiousness, openness, and agreeableness were important predictors of the integrating strategy.

Although previous studies have shown that the integrating and compromising strategies are preferred when people face conflicts (e.g. Lee, 2003; Trubisky et al., 1991), the direct impacts of those two styles on job performance are under-researched. Rahim et al. (2001) contended the linkage between CMSs and job performance, but this relationship has not been tested directly. Other studies discussed the positive effects of integrating and compromising styles on conflict resolutions (Hocker and Wilmot, 1998; Gross and Guerrero, 2000), but not on job performance. This may cause theoretical limitation in explaining why individuals prefer to use integrating and compromising styles when resolving conflicts, particularly its relation with job performance. This study aims at closing the theoretical gap, contributing to the Management theory through developing the Conflict Management Resolution grid as a tool to be used in the selection and development of personnel in sales and marketing in specific, and identifying the effects of CMSs on job performance.

Despite the wide management interest, conflict between the marketing and sales functions in the food manufacturing industry has been little investigated. In addition, in food manufacturing academia, little attention is given to conflict management strategies and job performance especially in the marketing and sales organizations in tough selling conditions. Besides, there is a need for a reliable tool to use in selecting and developing the skills of personnel in the field of conflict management and resolution.

To investigate the relationship between CMSs, and job performance, data were collected from respondents working in the sales and marketing departments in Egypt. After reviewing the extant literature, it was found that previous research had not much focused on the relationship between CMSs, and job performance within the food manufacturing sector in tough selling conditions in specific(Jordan and Troth, 2004;Rahim et al., 2001). CMSs and job performance research should be extended to the domain of sales and marketing so as to generalize research findings, even though they are different in their goals in terms of functional interest versus organizational welfare (Rainey and Chun, 2005). In addition, Denhardt (1991, p. 15) further explicates the differences between private and public organizations in terms of "ambiguity, pluralistic decision making and visibility". Those differences may create different tensions among employees in those sectors, leading to different behaviors. This study, therefore, expects to verify whether CMSs can provide beneficial results and performance in the food manufacturing sector.

\section{Relevant Scholarship}

\subsection{The Nature of Conflict}

Conflict involves the interdependence of two parties and arises when the first party interferes or put barriers and obstacles in the way of the second party when he tries to achieve his tasks and objectives. There are two types of conflict: task and emotional. Task conflict focuses on systematic disagreement when achieving tasks while emotional conflict involves friction between people (Jehn, 1995). In most cases conflict is able to be resolved. In business contexts, there is no doubt that conflict exists among functional areas - specifically marketing and sales. But conflict and its consequences can be decreased when following effective conflict management strategies.

\subsection{The Conflict between Marketing and Sales Functions}

While improving the company's relationship with customers is an important endeavor, looking in the mirror at relationships within the business is equally important to success. Of specific concern is the relationship between the sales and marketing organizations. It must be solid to enable the development of the external bond to prospects and customers. Yet, in most businesses, this organizational synergy has been overlooked and is fraught with problems and results in costly acquisition of accounts, ineffective marketing expenditures, and inefficient operations.

This gap in operational effectiveness originates from a lack of agreed-upon profiles for qualified leads and is exacerbated by marketing's desire to support sales through the generation of high volume of leads. Sales representatives usually perceive the leads provided by marketing to be nothing more than mere contacts. The prospects are under qualified, unable or unwilling to buy in the short-term, are not the decision-makers in the company, while already having competing products installed. The concept fundamentally conflicts with the roles 
and objectives of marketing and sales, and how conflict could be handled by competent and high performing staff and managers using effective conflict management strategies.

Focusing on the working relationship between Marketing Managers and Sales Managers, Massey and Dawes (2007) examine two dimensions of interpersonal conflict: dysfunctional conflict and functional conflict. According to relevant theory, three communication variables: frequency, bi-directionality, and quality are included as antecedents in their structural model. Using these explanatory variables, they predict the two conflict dimensions, and in turn, use those three communication variables, and the two conflict dimensions to predict their ultimate endogenous variable: perceived relationship effectiveness. Their model has high explanatory power as it proved support for nine of the thirteen hypotheses. Two of the three communication variables: communication quality and bi-directionality significantly affect both forms of conflict, and relationship effectiveness. Communication frequency only positively influenced the quality of communication between the Marketing Managers and the Sales Managers. In addition, the variables in this model better predict the levels of functional conflict in the Marketing/Sales relationship than dysfunctional conflict. Finally, an important new finding is that the overall level of dysfunctional conflict between these two functional managers is relatively low, while functional conflict is high.

The researcher introduces practical techniques that can be implemented to resolve the conflict between two functions, in specific marketing and sales. It comprises 4 stages:

1) Identifying the major duties and responsibilities of the 2 functions where conflict exists.

2) Determining the area(s) of conflict between the 2 functions.

3) Dividing up the conflict area(s) into 3 levels:

a. Major conflict points that usually represent $50-60 \%$ of the total conflict.

b. Intermediate conflict points that usually represent $30-40 \%$ of the total conflict.

c. Minor conflict points that usually represent about $10 \%$ of the total conflict.

4) Identifying the priorities to start within the implementation stage. In this stage, the focus is on the third party that will be in charge with managing or coordinating the conflict resolution process. The third party can be either:

a. An internal party: A selected committee, team, or unit involving well selected, trained, and highly qualified responsible people that will be in charge of resolving the conflict between the two parties that suffer from the existing conflict. To facilitate the resolution with the consideration of sensitivity to the situation, the resolution process should move through a bottom- up channel. The process starts with resolving the minor conflict points (area c), to the intermediate conflict points (area b), up to reaching the major conflict points (area a).

b. An external party: Specialized behavioral consultants in the field of conflict resolution that are experts in penetrating the conflict areas, strongly and effectively. The conflict management resolution process usually starts with (area a): the major conflict points; or (area b): the intermediate conflict points, then the major (area a); then moving down to (area c): the minor conflict points. These consultants represent a professional neutral third party.

\subsection{The Role of Human Resource Management}

The responsibility for organizational success or failure is shared between the personnel function, and other enterprise functions, mainly marketing and sales. The former president of the American Management Association once said: "Management is Personnel Administration" (Appley, 1969). His meaning, of course, was that all managers have personnel responsibilities, just as personnel directors must also be competent managers. Every manager must motivate and direct his workforce, even as every manager is responsible for the final decision in recruiting, staffing, training, and performance appraisal. Developing a personnel function is a way of providing services to line and other managers in the way of programs, policies and procedures that enable a line manager to do his job more effectively. Sometimes, of course, the help provided by personnel is in the form of expertise. Personnel policies and programs must be initiated upon the needs of various functions, then designed, implemented and supported by line managers. The success of such personnel policies and programs as in staffing and training programs should, depend on such personnel needs of line managers, mainly sales and marketing managers.

\subsection{Conflict Management Strategies}

Several typologies of conflict management have been developed (Rahim and Bonoma, 1979; Thomas 1976, 
1979). Most of these typologies involve two dimensions based on the concern for self and for the other party's needs. The conflict management strategies include 5 major strategies: (1) Competition (Ganesan, 1993)sometimes described as forcing (Blake and Mouton,1964), confrontation (Thomas, 1992), win-lose (Hall, 1969), dominating (Rahim and Bonoma, 1979), or contending (Pruitt, 1983).We term this strategy "competition" suggesting that salespeople and marketing people using this approach remain steadfast, but not necessarily adversarial; (2) Accommodation (Ganesan, 1993), smoothing over (Blake and Mouton, 1964), yield losing (Hall, 1969), obliging (Rahim and Bonoma, 1979), or yielding (Pruitt,1983). This accommodation conflict management strategy attempts to satisfy the other party's concerns, while neglecting one's own concern in conflict situations; (3) Compromise, sufficing (Spitzberg and Canary, 1985) or sharing (Thomas, 1976), attempts to attain moderate but not total satisfaction of parties' concerns, giving up something but also holding out for something (Blake and Mouton, 1964; Hall, 1969; Rahim and Bonoma, 1979; Thomas, 1976); (4) Avoidance, neglects both parties concerns, conflict is still not resolved and the two parties disagree about many issues (5) Collaboration(Thomas, 1976), problem solving (Dant and Schul, 1992; Pruitt, 1983), synergistic (Hall, 1969), or integrating (Rahim and Bonoma, 1979). It involves searching for integrative, win-win resolutions of conflict that fully satisfy the concerns of the two parties in disagreement by expanding the level of joint outcomes.

A Conflict Management Grid is introduced, then a conceptual framework specifying the relationships between the constructs is developed. Hypotheses related to the principal contribution of this research, the effects of the conflict management strategies are outlined following the discussion of potential direct effects of the conflict management strategies and job performance levels.

\subsection{Conflict Management Grid (CMG)}

This research develops a Conflict Management Grid using two dimensions: Cooperation and Assertiveness. Every dimension can be measured using a 9 point scale where 9 means high, 5 means medium and 1 means low. The grid includes five strategies. This research proposes that the acquisition and the use of every strategy can be measured using the same suggested scale as follows: Avoidance $(1,1) \mathrm{C}$ - A- (low cooperation and low assertiveness); Accommodation $(9,1) \mathrm{C}+\mathrm{A}$ - (high cooperation and low assertiveness); Competition $(1,9) \mathrm{C}-\mathrm{A}+$ (low cooperation and high assertiveness); Collaboration /Integration $(9,9) \mathrm{C}+\mathrm{A}$ - (high cooperation and high assertiveness); and Compromise $(5,5) \mathrm{C} \mathrm{A}$ (medium cooperation and medium assertiveness).

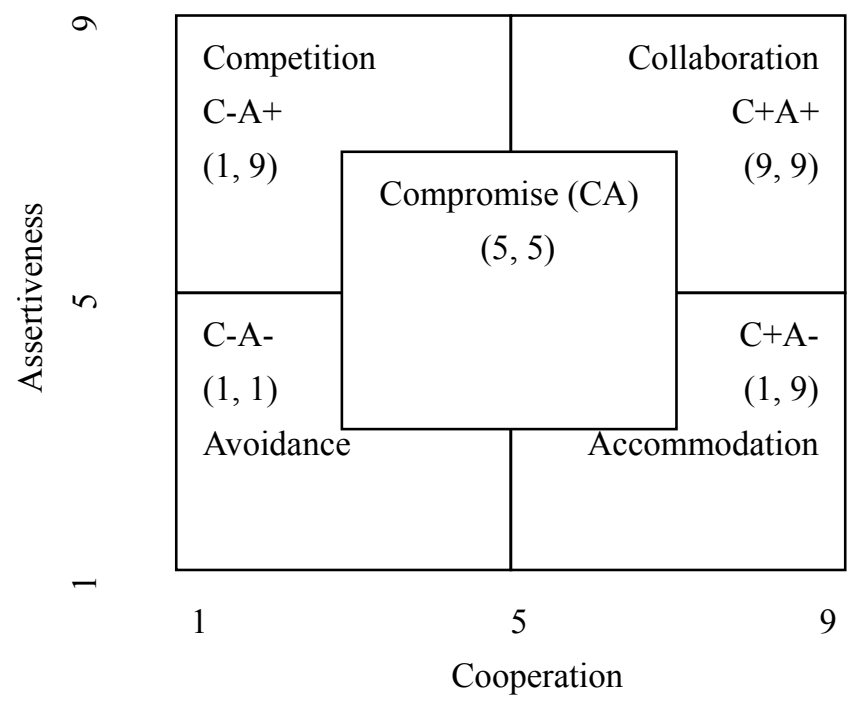

Figure 1. The conflict management grid (CMG) 


\section{Hypotheses and their correspondence to research design}

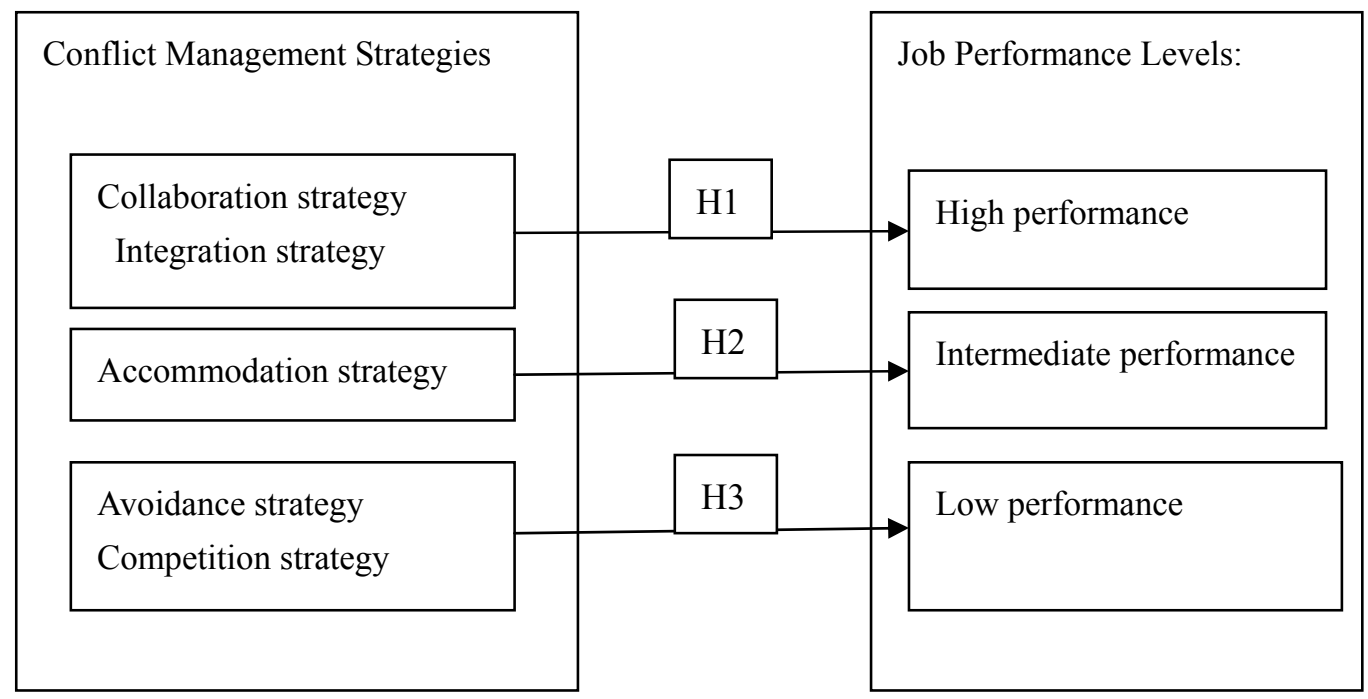

Figure 2. The conflict management strategies and job performance levels

Organizational behavior and human resource management scholars have different perspectives about the relationship between conflict and organizational performance. Some scholars have claimed that organizational conflict tended to hinder organizational performance and therefore should be avoided (Dyck et al., 1996; Robbins, 1991). Other scholars have viewed conflict as functional to organizations if it is managed properly (Jehn, 1995, 1997). They argue that conflict has an important role in optimizing organizational performance through developing "critical evaluation which decreases the groupthink phenomenon by increasing thoughtful consideration of criticism and alternative solutions" (Jehn, 1995, p. 260). To make conflict more productive, Jordan and Troth (2002) further suggest that the strategy used to handle interpersonal conflict is a crucial factor in successful conflict resolution. The integrating strategy of conflict management improves job performance when the solution to a conflict would benefit both parties. Both conflicting parties are encouraged to satisfy their interests through exchanging information (Meyer, 2004). Satisfaction from resolving conflicts may lead individuals to exert greater efforts in achieving performance. For example, Weider-Hatfield and Hatfield (1995) found that the integrating strategy had a strong association with job satisfaction and job performance. However, that study did not provide any clear relationship of the integrating strategy to job performance, so it lacked theoretical and empirical explanations. Rahim et al. (2001) also demonstrated that problem solving measured in terms of using more integrating strategy and less avoiding strategy, had a positive effect on the job performance.

Although very few empirical studies have presented the impact of compromising strategy on job performance, many studies have found that employees prefer to use the compromising strategy in resolving conflict (e.g. Lee, 2003; Trubisky et al., 1991). Kim et al. (2007) compared three different groups in terms of conflict management strategies at the workplace and found that the compromising strategy was used often when conflicts existed between employees and supervisors. The compromising strategy may produce beneficial results due to the fact that this strategy helps conflicting people quickly find solutions and provide benefits to both sides through concessions (Hocker and Wilmot, 1998; Gross and Guerrero, 2000; Rahim, 2002). Quick and acceptable solutions resulting from using the compromising strategy may stimulate individuals to exert greater effort in achieving performance. Based on those arguments, it can be proposed that both the collaboration and compromising strategies of conflict resolution will be positively related to job performance.

Thus, the following hypothesis can be posed:

H1 The organizations that have a Channel Category Sales Development (CCSD) unit whose team(s) members use effective conflict management strategies(to decrease conflict between marketing and sales functions) will positively affect job performance levels in the marketing and sales functions.

H1a The use of the conflict management strategies: compromise and collaboration will likely be associated with high job performance level in the marketing and sales functions. 
H1b The use of the accommodation style will likely be associated with intermediate job performance level in the marketing and sales functions.

H1c The use of the conflict management strategies: avoidance and competition will likely be associated with low job performance level in the marketing and sales functions.

\section{Method}

\subsection{Participants' Characteristics, Sampling Procedures, and Sample Size and Power}

The food manufacturing industry in Egypt compromises 59 organizations (www.mbendi.com). Both food manufacturing organizations that have and do not have a Channel Category Sales Development (CCSD) unit have been included in the study. The CCSD unit is a unit created within the organizational chart of an organization and charged with resolving conflict between marketing and sales functions.

Personal interviews were held with 30 marketing and sales managers in food manufacturing organizations that created a CCSD unit or a similar unit and those which did not create this unit. It was found that in the organizations that create a CCSD unit, the level of conflict between the marketing and sales functions is low and the CCSD succeeds in resolving conflict that in turn leads to higher performance within both functions. On the other hand, the organizations that do not have a CCSD unit, suffer from high levels of conflict between the marketing and sales functions that in turn, affects the efficiency and effectiveness of performance in both functions.

The research population chosen for the empirical research included: marketing managers, assistant brand managers, sales representatives, and Channel Category Sales Development (CCSD) unit team members in the food manufacturing industry in Egypt. Among 29 governorates (where every governorate represents a region) 10 regions were chosen for this study. Every region involves, on the average, four districts. The study focuses on 40 districts in total.

The questionnaire was modified to suit the Egyptian environment and the food manufacturing industry in Egypt. Consequently, the revised questionnaire was distributed among 50 marketing managers, assistant brand managers, sales representatives, and CCSD team members to pretest it. Data were gathered through personal interviews. The questionnaire was revised and modified again before distributing it at a large scale.

The questionnaire was distributed among 450 randomly selected sample units: 55 marketing managers, 185 assistant brand managers, 175 sales representatives, and 35 Channel Category Sales Development (CCSD) team members.

410 marketing managers, assistant brand managers, sales representatives, and Channel Category Sales Development (CCSD) team members filled in the questionnaires. 390 answered questionnaires are usable. The response rate is about $86 \%$. The data collected was revised and analyzed using the SPSS statistical software package.

Concerning the sample profile, $72 \%$ are male, $73 \%$ hold a bachelor degree in Business, Marketing or IT, $24 \%$ hold an MBA degree, and 3\% hold a Ph.D. degree. $60 \%$ are in their 30 s, $33 \%$ are in the 20 s, $83 \%$ possess 10 years of experience or less and $17 \%$ possess 15 years of experience or more.

\subsection{Measures and Covariates}

A measurement instrument consisting of a multi- dimensional scale is used. Two constructs are included in this study: (1) conflict management strategies, and (2) job performance. A 5-point Likert scale was used throughout the questionnaire where 5 means strongly agree and 1 means strongly disagree.

Conflict management handling strategies. A multidimensional 20-item measure developed by Whetten and Cameron (2009) was used. Conflict management strategies are consisted of five variables: competition strategy, accommodating strategy, collaboration strategy, avoidance strategy, and compromise strategy. Competition strategy is consisted of 4 items, accommodation strategy is composed of 4 items, collaboration strategy is composed of 4 items, avoidance strategy comprises 4 items, and compromise strategy involves 4 items. The Cronbach's Alfa of the conflict management strategies is (.78).

Job Performance. Job performance was measured through 8 evaluation items developed by Fried et al. (1998). It is a superior assessment scale focusing on such items as quantity and quality of work, meeting deadlines, and problem solving. A 5 point Likert scale was used where 5 means outstanding, 4 means high, 3 means satisfactory, 2 means low, and 1 means very low. The Cronbach's Alfa of the job performance is (.71). 


\section{Results}

\subsection{Data Analysis}

Table 1 shows the bivariate correlation among scaled variables. The correlation analysis proved evidence of a significant correlation between independent and dependent variables. The correlation matrix revealed high positive correlation between collaboration and compromise strategies and high performance; accommodation strategy and intermediate level of performance, and competition and avoidance strategies and low level of performance.

Table 1. Intercorrelations among scaled variables

\begin{tabular}{|c|c|c|c|c|c|c|c|c|c|c|}
\hline & 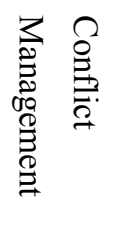 & 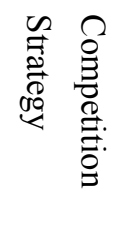 & 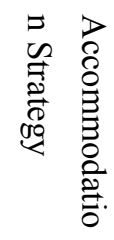 & 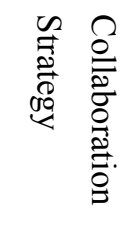 & 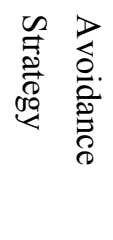 & 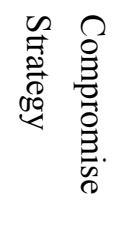 & $\begin{array}{l}0 \\
0 \\
\stackrel{0}{0} \\
\stackrel{0}{0} \\
\stackrel{0}{0} \\
0\end{array}$ & 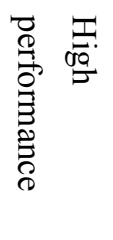 & 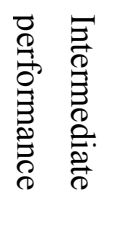 & 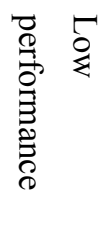 \\
\hline $\begin{array}{l}\text { Conflict } \\
\text { Management } \\
\text { Strategies }\end{array}$ & 1 & & & & & & & & & \\
\hline $\begin{array}{l}\text { Competition } \\
\text { Strategy }\end{array}$ & $.600^{* *}$ & 1 & & & & & & & & \\
\hline $\begin{array}{l}\text { Accommodation } \\
\text { Strategy }\end{array}$ & $.857 * *$ & $.406^{*}$ & 1 & & & & & & & \\
\hline $\begin{array}{l}\text { Collaboration } \\
\text { Strategy }\end{array}$ & $.744 * *$ & .189 & $.660 * *$ & 1 & & & & & & \\
\hline $\begin{array}{l}\text { Avoidance } \\
\text { Strategy }\end{array}$ & $.644 * *$ & .043 & $.482 * *$ & .318 & 1 & & & & & \\
\hline $\begin{array}{l}\text { Compromise } \\
\text { Strategy }\end{array}$ & $.615^{* *}$ & .056 & $.394 *$ & $.866^{* *}$ & $.470^{* *}$ & 1 & & & & \\
\hline Performance & $.673 * *$ & $-.104 *$ & $.139 *$ & $.312 * *$ & $-.199 *$ & $.230 * *$ & 1 & & & \\
\hline $\begin{array}{l}\text { High } \\
\text { performance }\end{array}$ & $.639 * *$ & $-.120^{*}$ & $.357^{*}$ & $.868 * *$ & $-.289 *$ & $.810 * *$ & $.725 * *$ & 1 & & \\
\hline $\begin{array}{l}\text { Intermediate } \\
\text { performance }\end{array}$ & $.471^{*}$ & $.218^{*}$ & $.712 * *$ & $.301 *$ & $.422 *$ & $.201 * *$ & $-.486^{* *}$ & $.522 * *$ & 1 & \\
\hline Low performance & $-.383 * *$ & $.635^{*}$ & $-.249 *$ & $-.364 *$ & $.691 * *$ & $-.258^{*}$ & $-.655^{*}$ & .068 & .269 & 1 \\
\hline
\end{tabular}

$* *$ Correlation is significant at the 0.01 level (2-tailed).

*Correlation is significant at the 0.05 level (2-tailed).

Table 2. Testing the relationship between the collaboration and compromise strategies and high performance

\begin{tabular}{|c|c|c|c|c|c|c|}
\hline \multicolumn{7}{|c|}{ ANOVA $^{\text {b }}$} \\
\hline & & Sum of Squares & df & Mean Square & $\mathrm{F}$ & Sig. \\
\hline \multirow[t]{3}{*}{1} & Regression & 1.530 & 2 & .765 & 1.011 & $.001^{\mathrm{a}}$ \\
\hline & Residual & 21.939 & 29 & .757 & & \\
\hline & Total & 23.469 & 31 & & & \\
\hline
\end{tabular}

a. Predictors: (Constant), Compromise Strategy, Collaboration Strategy

b. Dependent Variable: high performance 
Table 3. Testing the relationship between the collaboration and compromise strategies and high performance

Coefficients $^{\text {a }}$

\begin{tabular}{|c|c|c|c|c|c|c|}
\hline \multirow{2}{*}{\multicolumn{2}{|c|}{ Model }} & \multicolumn{2}{|c|}{ Unstandardized Coefficients } & \multirow{2}{*}{$\begin{array}{c}\text { Standardized } \\
\text { Coefficients } \\
\text { Beta }\end{array}$} & \multirow[b]{2}{*}{$\mathrm{t}$} & \multirow[b]{2}{*}{ Sig. } \\
\hline & & $\mathrm{B}$ & Std. Error & & & \\
\hline & (Constant) & .490 & 1.369 & & 3.279 & .185 \\
\hline & Collaboration Strategy & .780 & .080 & .908 & 1.357 & .001 \\
\hline & Compromise Strategy & .777 & .060 & .891 & 1.256 & .001 \\
\hline
\end{tabular}

a. Dependent Variable: high performance

Table 4. Testing the relationship between the accommodation strategy and intermediate performance

Coefficients $^{\text {a }}$

\begin{tabular}{llccccc}
\hline \multicolumn{1}{c}{} & \multicolumn{5}{c}{ Standardized } \\
Model & & Unstandardized Coefficients & Coefficients & \\
\hline 1 & & B & Std. Error & Beta & $\mathrm{t}$ & Sig. \\
& (Constant) & 2.518 & .059 & & 2.899 & .017 \\
& Accommodation & .380 & .868 & .604 & .639 & .001 \\
& Strategy & & & & & \\
\hline
\end{tabular}

a. intermediate performance

The analysis of variance (Table 2) shows that the overall model is significant when the independent variables: the collaboration and compromise strategies were entered into the regression equation. The results provide support for the relationship in hypothesis 1a (Overall model: $\mathrm{F}=1.011$, $\mathrm{df}=2, \mathrm{p}<0.001 ; \mathrm{R}^{2}=.650$, adjusted $\mathrm{R}^{2}=.633$ ). $\mathrm{R}$ - Squared measures the proportion of variance in the dependent variable that is explained by changes in all of the explanatory variables. In the full model, the relationship between the conflict management strategies: collaboration and compromise and job performance, is supported in the sales and marketing functions of organizations that created a CCSD unit. Therefore, H1a is supported.

The global test assures that the independent variables do have the ability to explain the variation in the dependent variable (Lind et al., 2006). Thus, there is enough evidence that both the collaboration and compromise strategies are significantly related to, associated with and have a significant impact on job performance (see Table 3 ). The higher the use of the collaboration and compromise strategies the higher the cooperation and assertiveness and consequently the higher the job performance level of the marketing, sales personnel, and CCSD unit staff members. Table 3 shows that the model is significant when an accommodation strategy was entered into the regression equation. The results provide evidence for the relationship in hypothesis $1 \mathrm{~b}$ (Overall model: $\mathrm{F}=1.108$, $\mathrm{df}=1, \mathrm{p}<0.001 ; \mathrm{R}^{2}=.700$, adjusted $\mathrm{R}^{2}=.683$ ). $\mathrm{R}$ - Squared measures the proportion of variance in the job performance levels that is explained by changes in all of the explanatory variables. The relationship between the conflict management strategy: accommodation and intermediate job performance, is supported in the sales and marketing functions of organizations that believe in the importance of creating a CCSD unit and who plan to create such a unit. Therefore, H1c is supported. There is enough evidence that the higher the use of the accommodation strategy in managing conflict between the marketing and sales functions, the higher the degree of cooperation. Conversely, as organizations avoid the use of the competition and /or the avoidance strategy, the degree of assertiveness is lower, and as a result an intermediate level of performance will occur. Thus, the use of the accommodation strategy in managing conflicts is a significant predictor of the intermediate level of job performance in marketing and sales departments. The overall model is significant when the independent variables: the competition and avoidance strategies were entered into the regression equation. The results provide evidence for the relationship in hypothesis $1 \mathrm{c}$ (Overall model: $\mathrm{F}=2.425, \mathrm{df}=2, \mathrm{p}<0.005 ; \mathrm{R}^{2}=.730$, adjusted $\mathrm{R}^{2}=.703$ ). $\mathrm{R}$ - Squared measures the proportion of variance in the job performance levels that is explained by 
changes in all of the explanatory variables. The relationship between the conflict management strategies: competition and avoidance, and job performance is supported, in the sales and marketing functions of organizations that did not create a CCSD unit.

\section{Discussion}

The research concludes with the following points:

- In the food manufacturing organizations that created a CCSD unit, the level of conflict between the marketing and sales functions is reduced and the CCSD succeeds in resolving conflicts, consequently lead to higher performance within both functions. On the other hand, the organizations that do not have a CCSD unit, suffer from high levels of conflict between the marketing and sales functions that in turn, affect the level of performance in both functions.

- The five conflict management strategies used to resolve conflicts between the marketing and sales functions have different effects according to the type of strategy used. The type of conflict management strategies used by the marketing and sales staff influence their performance (high-medium-low).

- The positive and highly influential management strategies: collaboration and compromise, lead to higher staff performance of the marketing and sales functions. Any deficiency and /or problem in using those two strategies should be remedied immediately. The use of the collaboration strategy in conflict resolution will increase the effectiveness of both functions: marketing and sales, in addition to reducing the level of conflict to a great extent.

- The two conflict management strategies: avoidance and competition, when used to manage conflicts between the marketing and sales functions, have a negative influence on the performance of both staff and functions. Using the avoidance strategy leads to more hidden conflict that will consequently influence the productivity of the staff in both the marketing and sales functions and decrease effectiveness.

- Using the accommodation strategy to manage and resolve conflicts between the marketing and sales functions leads to postponing the conflict rather than resolving it. This strategy leads to a "pause" situation that, in turn, hinders an organization's improvement and negatively influences its marketing and sales performance. Therefore, it finally leads to marketing outdate instead of update.

\section{Recommendations, Managerial Implications, and Future Research}

To close the gap between the sales and marketing, they both must identify and agree on the specific characteristics, attributes and profiles of highly qualified prospects. Successful marketing calls for the establishment of well-defined goals, that are agreed upon by both sales and marketing, make a significant contribution to the organization success.

For the organizations that possess a CCSD unit, they should keep on recruiting and selecting competent and highly qualified human resources at all levels: managerial, supervisory, and executive. On the other hand, for the organizations that do not possess a CCSD unit, immediate creation of this unit is crucial and staffing it with highly qualified, competent, and well trained human resource is essential. Training, coaching and mentoring programs can enhance and improve the use and application of conflict management strategies by staff, supervisors and managers. Financial and non-financial rewards can also motivate the personnel in both functions.

To lessen the degree of functional conflict, effective human resource management strategies, activities, and practices such as human resource planning, recruitment, effective selection (tests and interviews) of new employees and assessment centers for managers to be hired at the CCSD unit. The human resource department should continually design; administer a self- appraisal performance system, a continual training and development needs' assessment, and an incentive scheme that relate reward to performance and performance improvement. The proposed conflict resolution grid is useful in recruiting, selecting, hiring, training and appraising performance of managers, supervisors, and staff in measuring and developing conflict resolution especially in marketing and sales.

Sales managers should work on a preventive approach to reduce conflicts as it will help improve the relationship between the sales and marketing functions. Consequently, sales are expected to reach their target levels even higher. Sales managers can use the proposed grid/matrix in hiring, appraising and improving the performance of their staff, and in training and developing their sales force. It explains how effective conflict strategies as compromise and collaboration strategies work and help achieving targets effectively and how ineffective conflict strategies such as avoidance or competition don't work. In other words, if a sales manager is faced with high to medium conflicts inside his organization or between his organization and the marketing one, he has to adopt a conflict reduction strategy. The sales manager or supervisor can recommend that every staff member, using the 
proposed conflict management grid developed, fills in 2 forms. The first is a self assessment form where he determines what strategy (ies) he or she uses in most cases and locates it on the grid and the degree of its usage. The second is a performance improvement plan form where he and his superior design it together.

A periodical joint meeting between the marketing and sales staff is recommended as a part of a preventive and positive approach of problem solving and conflict resolution. Joint training and development courses and sessions are beneficial. In addition, a part of the rewards and salary increases of the Marketing and sales staff should be tied to their degree of collaboration. In case a party refuses to work with the other, a third party like an internal committee or an external party like an outside consultant can help in solving this dilemma. If, unexpectedly, after professional intervention, he still refuses to collaborate, he should be replaced.

The problem of conflict between marketing and sales functions should be studied through a longitudinal survey. A further study could also measure employees and staff attitudes in the CCSD units toward the conflict management strategies, techniques, and processes used to resolve conflict between the marketing and sales functions using the conflict management resolution matrix. Research should also be expanded to other industries, product or service organizations to increase the generalizability of the findings.

\section{Acknowledgement}

The author would like to thank Professor Earl Honeycutt, Professor of Marketing, Department of Marketing \& Entrepreneurship, School of Business, Elon University, North Carolina, USA; for reviewing the first draft of this manuscript and providing valuable insights.

\section{References}

Blake, R.R., \& Jane, S. M. (1964). The managerial grid. Gulf, Houston: TX.

Bobot, L. (2010). Conflict management in buyer-seller relationships. Conflict resolution quarterly, 27(3), 291-319. http://dx.doi.org/10.1002/crq.260

Boroş, S., Meslec, N., Curşeu, P., \& Emo, W. (2010). Struggles for cooperation: conflict resolution strategies in multicultural groups. Journal of managerial psychology, 25(5), 539-554. http://dx.doi.org/10.1108/02683941011048418

Dant, R. P., \& Patrick, L. S. (1992). Conflict resolution processes in contractual channels of distribution. Journal of marketing, 56(1), 38-54. http://dx.doi.org/10.2307/1252131

Denhardt, R.B. (1991). Public administration: An action orientation. Brook/Cole Publishing Company, Monterey: CA.

Dyck, B., Bruning, N.S., \& Driedger, L. (1996). Potential conflict, conflict stimulus, and organizational performance: an empirical test. International journal of conflict management, 7(4), 295-313. http://dx.doi.org/10.1108/eb022785

Fried, Y., Ben, D., Haim, T., Robert, A., \& Yeverechyaho, U. (1998). The interactive effect of role conflict and role ambiguity on job performance. Journal of occupational and organizational psychology, 71, 19-27. http://dx.doi.org/10.1111/j.2044-8325.1998.tb00659.x

Ganesan, S. (1993). Negotiation strategies and the nature of channel relationship. Journal of marketing research, 30(2), 183-203. http://dx.doi.org/10.2307/3172827

Gross, M.A., \& Guerrero, L.K. (2000). Managing conflict appropriately and effectively: an application of the competence model to Rahim's organizational conflict styles. International journal of conflict management, 11(3), 200-226. http://dx.doi.org/10.1108/eb022840

Hall, J. (1969). Conflict management survey: A survey of one's characteristic reaction to and handling of conflicts between himself and others. Teleometrics, Houston: TX.

Hocker, J.L., \& Wilmot, W.W. (1998). Interpersonal conflict (5th ed.) Brown \& Benchmark, Madison: WI.

Jehn, K.A. (1995). A multimethod examination of the benefits and detriments of intragroup conflict. Administrative science quarterly, 40(2), 256-282. http://dx.doi.org/10.2307/2393638

Jehn, K.A. (1997). A qualitative analysis of conflict types and dimensions in organizational groups. Administrative science quarterly, 42(3), 530-57. http://dx.doi.org/10.2307/2393737

Jordan, P.J., \& Troth, A.C. (2002). Emotional intelligence and conflict resolution: implications for human resource development. Advances in developing human resources, 4(1), 62-79. http://dx.doi.org/10.1177/1523422302004001005 
Jordan, P.J., \& Troth, A.C. (2004). Managing emotions during team problem solving: emotional intelligence and conflict resolution. Human performance, 17(2), 195-218. http://dx.doi.org/10.1207/s15327043hup1702_4

Kim, T.Y., Wang, C., Kondo, M., \& Kim, T.H. (2007). Conflict management styles: the differences among the Chinese, Japanese and Koreans. International journal of conflict management, 18(1), 23-41. http://dx.doi.org/10.1108/10444060710759309

Le Nguyen, H., \& Larimo, J. (2011). Determinants of conflict management strategies in international joint ventures: An integrative theoretical framework. Journal of transnational management, 16(2), 116-132. $\mathrm{http}: / / \mathrm{dx}$.doi.org/10.1080/15475778.2011.571642

Lee, F.M. (2003). Conflict management styles and emotional intelligence of faculty and staff at a selected colleges in Southern Taiwan. Unpublished doctorate dissertation. University of South Dakota, Vermillion: SD.

Leung, K., \& Tjosvold, D. (1998). Introduction: conflict management in the Asia Pacific. In Leung, K. and Tjosvold, D. (Eds.), Conflict management in the Asia Pacific: Assumption and approaches in diverse culture. John Wiley \& Sons (Asia), New York: NY.

Massey, G.R., \& Dawes, P. L. (2007). The antecedents and consequence of functional and dysfunctional conflict between Marketing managers and Sales managers. Industrial marketing management, 36(8), 1118-1129. $\mathrm{http}: / / \mathrm{dx}$.doi.org/10.1016/j.indmarman.2006.05.017

Mayer, J.D., Salovey, P., \& Caruso, D.R. (2004). Emotional intelligence: theory, findings, and implications. Psychological inquiry, 60(3), 197-215. http://dx.doi.org/10.1207/s15327965pli1503_02

Merlo, Bob. (2005). Bridge the sales-marketing divide. Selling, (2), 14

Meuse, A. T., \& Walby, J. (2011). Leading the way. Business monthly. The American Chamber of Commerce in Egypt. April.

Meyer, S. (2004). Organizational response to conflict: future conflict and work outcomes. Social work research, 28(3) 183-90. http://dx.doi.org/10.1093/swr/28.3.183

Moberg, P.J. (2001). Linking conflict strategy to the five-factor model: theoretical and empirical foundations. International journal of conflict management, 12(1), 47-68. http://dx.doi.org/10.1108/eb022849

Rahim, M. A., \& Thomas, V. B. (1979). Managing organizational conflict: a model for diagnosis and intervention. Psychological reports, 44(3), 1323-1344. http://dx.doi.org/10.2466/pr0.1979.44.3c.1323

Rahim, M.A. (2002). Toward a theory of managing organizational conflict. International journal of conflict management, 13(3), 206-35. http://dx.doi.org/10.1108/eb022874

Rahim, M.A., Antonioni, D., \& Psenicka, C. (2001). A structural equations model of leader power, subordinates' styles of handling conflict, and job performance. International journal of conflict management, 12(3), 191-211. http://dx.doi.org/10.1108/eb022855

Rahim, M.A., Psenicka, C., Polychroniou, P., Zhao, J.H., Yu, C.S., Chan, K.A., .. Wyk, R.V. (2002). A model of emotional intelligence and conflict management strategies: a study in seven countries. International journal of organizational analysis, 10(4), 302-26. http://dx.doi.org/10.1108/eb028955

Rainey, H.G., \& Chun, Y.H. (2005). Public and private management compared. In Ferlie, E., Lynn, J., Lynn, L.E., and Pollitt, C. (Eds.), The Oxford Handbook of Public Management. Oxford University Press, New York: NY.

Robbins, S.P. (1991). Organizational behavior: concepts, controversies and applications (5th ed.). Prentice-Hall, Englewood Cliffs: NJ.

Spitzberg, B. H., \& Daniel J. C. (1985). Loneliness and relationally competent communication. Journal of social and personal relationships, 2(4), 387-402. http://dx.doi.org/10.1177/0265407585024001

Stern, L. W., El-Ansary, A., \& Coughlan, A. (1996). Marketing channels (5th ed.). Upper Saddle River, NJ: Prentice Hall.

Thomas, K. W. (1979). Conflict, in Organizational Behavior. In Steven Kerr (ed.). Grid Publications, Columbus: $\mathrm{OH}$.

Thomas, Kenneth W. (1992). Conflict and negotiation processes in organizations, in Handbook of Industrial and Organizational Psychology (2nd ed.). In Marvin D. Dunnette and Laetta M. Hough (Eds.), Consulting Psychology Press, Palo Alto: CA. 
Tjosvold, D. (1998). Cooperative and competitive goal approach to conflict: accomplishments and challenges. Applied psychology: an international review, 47(3), 285-342.

Trubisky, P., Ting-Toomey, S., \& Lin, S. L. (1991). The influence of individualism-collectivism and self-monitoring on conflict styles. International journal of intercultural relations, 15(1), 65-84. http://dx.doi.org/10.1016/0147-1767 (91)90074-Q

Weider-Hatfield, D., \& Hatfield, J.D. (1995). Relationships among conflict management styles, levels of conflict, and reactions to work. The Journal of social psychology, 135(6), 687-698. http://dx.doi.org/10.1080/00224545.1995.9713972

Whetten, David, \& Cameron, Kim. (2009). Developing management skills (8th ed.). Prentice Hall, NJ: NJ. 